\title{
メタ分析による認知的感情制御尺度と 抑うつ・不安の関連の検討
}

\author{
榊原 良太 $^{1}$ 北原 瑞穂 東京大学
}

\section{The relationship between Cognitive Emotion Regulation Questionnaire (CERQ) and depression, anxiety: Meta-analysis}

\author{
Ryota Sakakibara and Mizuho Kitahara (University of Tokyo)
}

\begin{abstract}
This study aimed to investigate the relations between CERQ and depression, and anxiety, and also aimed to reveal the characteristics of a Japanese sample through meta-analysis. The results showed that self-blame, acceptance, rumination, catastrophizing, and blaming others had significantly positive correlations with both depression and anxiety, whereas positive refocusing, refocus on planning, positive reappraisal, and putting into perspective had significantly negative correlations with both variables. Moreover, when comparing the correlation coefficients of the Japanese samples and the combined value, correlations between depression and positive reappraisal were significantly larger than the combined value. On the other hand, regarding the correlation coefficients of depression and putting into perspective, the combined value was larger than the value of Japanese samples. In addition, compared to the combined value, the Japanese sample's positive correlation between anxiety and rumination, and negative correlation between anxiety and positive reappraisal were larger.
\end{abstract}

Key words: Cognitive Emotion Regulation Questionnaire (CERQ), depression, anxiety, meta-analysis.

The Japanese Journal of Psychology

2016, Vol. 87, No. 2, pp. 179-185

J-STAGE Advanced published date: March 10, 2016, doi.org/10.4992/jjpsy.87.15302

近年, 状況や出来事の意味を認知的に変化させるこ とによって, 感情の強さや種類を変える, 認知的感情 制御 (cognitive emotion regulation) への注目が高まって いる (Ochsner \& Gross, 2008; 柇原, 2014)。従来，種々の 認知的感情制御方略と精神的健康の関連が検討されて きた (Aldao, Nolen-Hoeksema, \& Schweizer, 2010; Anderson, Miller, Riger, Dill, \& Sedikides, 1994; Spasojević \& Alloy, 2001）。最近では，これらの知見がメンタルヘルス向 上の介入へ応用されるなど（Nelis et al., 2011），精神 的健康の維持・向上に打いて, 認知的感情制御研究は

Correspondence concerning this article should be sent to: Ryota Sakakibara, Graduate School of Education, University of Tokyo, Hongo, Bunkyo-ku, Tokyo 113-0033, Japan. (E-mail: ryota77@ p.u-tokyo.ac.jp)

本稿の執筆にあたり, 東京大学の遠藤 利彦先生より多くの ご指導をいただきました。また英文作成においては，東京大学 の石井 悠さんより貴重なご助言をいただきました。記して厚く 御礼申し上げます。
今後さらに重要な位置付けを担っていくと考えられ る。

従来の研究は，単独あるいは少数の方略に焦点を当 て，それらと精神的健康の関連を検討してきた。しか

し，日常生活では，多様な方略が使用され，それぞれ が精神的健康に影響を与えることが示唆されている

(Aldao \& Nolen-Hoeksema, 2013; Koole, 2009)。そのた め, 認知的感情制御と精神的健康の関連を検討する上 では，より多くの方略を含めた包括的なモデルを構築 していく必要がある (Garnefski \& Kraaij, 2007)。このよ うな問題意識のもとで作成されたのが, Garnefski, Kraaij, \& Spinhoven（2001）の Cognitive Emotion Regulation Questionnaire (CERQ) である。

Garnefski et al.（2001）は，それまでの感情制御研 究やコーピング研究を俯瞰し, 認知的感情制御が大 きく $9 つ の$ 方略に分類されることを理論駆動的に示 した。9つの方略とは, 自責 (self-blame), 受容 (acceptance), 反炰 (rumination or focus on thought), 肯定的再焦点化 (positive refocusing), 計画への再焦 
点化 (refocus on planning), 肯定的再評価 (positive reappraisal), 大局的視点 (put into perspective), 破局 的思考 (catastrophizing), 他者非難 (blaming others) である。自責は「ある出来事について自身を非難す る思考」，受容は「ある出来事を受け入れる，あるい は出来事に従おうとする思考」, 反炰は「ネガティブ な出来事に関する気持ちや思考について考えるこ と」, 肯定的再焦点化は「現実の出来事について考え ず楽しいことや嬉しいことを考えること」，計画への 再焦点化は「ネガティブな出来事にどのように対処 するか考えること」，肯定的再評価は「個人の成長と いう観点から出来事にポジティブな意味を置く思 考」，大局的視点は「出来事の重大さを軽視する，ま た他の出来事との相対性を強調する思考」, 破局的思 考は「極端にある出来事の悪い点を強調する思考」, 他者非難は「ある出来事について他者を非難する思 考」である。

CERQ の特長として, 以下の 2 つが挙げられる。ま ず，各方略の定義および方略間の違いを明確にした上 で尺度作成を行い，さらにその高い妥当性・信頼性が 繰り返し示されている点である (Garnefski \& Kraaij, 2007)。特に, 各方略の定義および方略間の違いが明 確である点は, 方略間の概念的重複を避ける上で重要 である。例えば従来の再評価研究では, 再評価の定義 の曖昧さに起因して, 実験での教示や尺度項目に, 眓 らずも受容や気晴らしなどの別の方略が反映されてき たことが指摘されている (Ochsner \& Gross, 2007; 柇原・ 石井, 2013)。そのため, 各方略の定義㧍よび方略間 の違いが明確な 9 つの方略を同時に測定できる点は, CERQ の重要な特長であると言えるだろう。また，一 般的に不適応的とされる方略が下位尺度に含まれてい る点が挙げられる。不適応的とされる方略が, 従来の 研究では相対的に見過ごされてきたこと，またそうし た方略が適応的とされている方略に比べて精神的健康 へ与える影響が大きいという知見 (Aldao et al., 2010) を踏まえると，この点は非常に大きな利点であると考 えられる。

これらのことから, CERQ は今後さらに多くの研究 で使用されていくことが予想される。しかしながら， CERQ の各方略と精神的健康の関連を検討した従来の 研究を俯瞰すると，その知見は必ずしも一様ではない という状況が窺われる。例えば Garnefski et al. (2001) では, 全ての下位方略が抑うつ・不安と正の相関係数 を示したが, Jermann, Van der Linden, d'Acremont, \& Zermatten（2006）では, 抑うつとの関連において, 受容, 肯定的再焦点化, 計画への再焦点化, 肯定的再 評価, 大局的視点では負の相関係数が, 自責, 反鄒, 破局的思考, 他者非難では正の相関係数が得られてい る。その他, CERQ と抑うつ・不安の関連を検証した 研究はこれまで Martin \& Dahlen（2005）, Tuna \& Bozo
（2012）など数多く行われているが，一貫した結果は 得られていない。こうした状況により，各方略と精神 的健康の関連における共通見解は未だ確立されておら ず，研究ごとにその性質への言及，考察がなされてい るのが現状である。そのため, 従来の知見を統合し, 各方略と精神的健康の関連が一般的にどの程度の大き さなのか，その具体的な值を算出することは，今後の CERQ 用いた研究や感情制御研究に有用な指標をも たらすと言えるだろう。

以上より本研究では, CERQ と抑うつ・不安の関連 についてメ夕分析を行うこととする。本来, wellbeing などのポジティブな指標との関連についてもメ 夕分析を行うべきであるが, CERQ とポジティブな指 標の関連を検証した研究は極めて少ない。そこで, こ れまで最も CERQ との関連が検討されてきた, 抑うつ. 不安との相関係数についてメ夕分析を行うこととし た。さらに本研究では, メ夕分析によって得られた值 を, 日本人を対象とした研究（榊原, 2015）の值と比 較することによって, 部分的にではあるが, 日本人サ ンプルの認知的感情制御の特性を検討する。これによ り, 日本人を対象にCERQを用いる今後の研究に対 して有益な知見がもたらされるとともに，文化間比較 という点についても一定の示唆が得られると考えられ る。

\section{方 法}

\section{文献収集}

2015 年 2 月に, Google Scholar および PsycINFO, ScienceDirectに扔いて, “cognitive emotion regulation questionnaire”というワードを用いて検索した。その 結 果, Google Scholar で 809 件, PsycINFO で 61 件, ScienceDirect で 92 件の文献がヒットした。さらに, Garnefski et al. (2001) および Garnefski \& Kraaij (2007) を引用している文献も確認した（Google Scholarにお いて Garnefski et al. (2001) が 553 件, Garnefski \& Kraaij（2007）が 130 件)。ヒットした全ての文献を確 認し，（a）CERQ を使用している，（b）英文の查読付 き論文である，という2つの基準で文献を収集し，重 複を除いたところ, 84 件の文献が得られた。さらに (c) 抑うつ・不安を自己報告式尺度によって測定している, (d) 一般サンプルを対象としており, 臨床群や特定の 状況（テロや口蹄疫被害など）を対象としたものでは ない, (e) 全ての調査対象者が 18 歳以上である, (f) 18 項目版の CERQ-short や子ども用の CERQ-k を用い たものではない，という基準を設定し，分析に含める 文献を収集した。必要な情報が報告されていない場合 は, 直接著者に問い合わせた。以上の手続きの結果, CERQ と抑うつの相関係数を報告した研究が 16 件, CERQ と不安の相関係数を報告した研究が 8 件収集さ 
れた2。

また，公表バイアスを考慮してトリム・アンド・フィ ル法による補正を行った。まず，公表バイアスのため に今回のメ夕分析に含まれなかった研究の数を, Duval \& Tweedie (2000)の R0 と L0 を用いて推定した。 大小いずれの相関係数が欠けているかについては, Egger, Smith, Schneider, \& Minder（1997）の回帰分析 を用いる方法によって漏斗プロットの非対称性を評価 した。含まれていない研究の数は, R0を用いると, 抑うつと自責, 受容, 肯定的再評価との相関係数でそ れぞれ 2 個, 他者非難との相関係数で 1 個, それ以外 は 0 個と推定された。L0を用いると, 抑うつと反㫚, 肯定的再焦点化, 肯定的再評価, 破局的思考, 他者非 難との相関係数で, それぞれ 4 個, 6 個, 5 個, 3 個, 2 個と推定され, 不安と反謅との相関係数で 3 個, 肯 定的再焦点化, 大局的視点, 他者非難との相関係数で それぞれ 1 個，それ以外は 0 個と推定された。それぞ れの方法で公表バイアスがあると推定された相関係数 について, 久測していると考えられる相関係数を代入 したうえで, 補正した平均効果量を推定したところ, 補正を行わない場合との相関係数の差の絶対值は最大 でも 0.07 であり, 相関係数の符号や有意性の有無が 変化したものはなかったため, 代入を行わないときの 結果のみを報告した。

\section{コーディング}

相関係数は一時点で同時に測定されたもののみを分 析に加えた。また，臨床群とコントロール群が設定さ れている場合, コントロール群のデー夕のみを分析に 加えた。なお， Jermann et al. (2009) において，同一 の調查対象者から CERQ と抑うつの相関係数が 2 つ 報告されていたため, 両者を $\mathrm{z}$ 変換した上で平均值を 算出し，それを逆変換した值を用いた。

\section{相関係数の統合}

相関係数の統合にあたり，研究間での効果量の等質

2 メ夕分析に含めた文献は, Besser \& Priel (2010), Garnefski \& Kraaij (2006a, 2006b), Jermann et al. (2006, 2009), Kàllay, łincaş, \& Benga (2009), Kàllay \& Vonas (2001), Kraaij, Pruymboom, \& Garnefski (2002), Lannoy et al. (2014), Lei et al. (2014), Martin \& Dahlen (2005), Miklósi, Martos, Szabó, Kocsis-Bogár, \& Forintos (2014), Rowland et al. (2013), Rukmini, Sudhir, \& Math (2014), Selby, Anestis, \& Joiner (2008), Tuna \& Bozo (2012), Tuna \& Bozo (2014), Westermann, Boden, Gross, \& Lincoln (2013) である。また, 抑うつ・不安の測定に用いられていた尺度は, 抑うつが Beck Depression Inventory, Beck Depression Inventory II, Brief Symptom Inventory, Depression Anxiety Stress Scales, Geriatric Depression Scale, Symptom Check List, The Center for Epidemiologic Studies Depression Scale, 不安が Beck Anxiety Inventory, Brief Symptom Inventory, Depression Anxiety Stress Scales, Negative State Mood, State-Trait Anxiety Inventory であった。
性を仮定しないランダム効果モデル (Raudenbush, 2009）を用いた。各方略と抑うつ・不安の従属変数と の組み合わせにおいて, 得られた相関係数を $\mathrm{z}$ 変換し た後に統合した。分析には, 統計解析ソフト Rの metafor パッケージ (Viechtbauer, 2010) を用いた。さ らに, 統合後の相関係数と, 榊原（2015）で得られた 相関係数の $\mathrm{z}$ 変換後の值の差を求め, それぞれの標準 誤差を用いて検定も行った。

\section{結 果}

収集された相関係数の個数，サンプルサイズ，下位 尺度と抑うつ, 不安との相関係数および $95 \%$ 信頼区 間を Table 1 に示す。なお，方略ごとに収集された相 関係数の個数が異なるのは, 研究によっては CERQ の特定の下位尺度（方略）のみを使用しているためで ある。いずれの相関係数の平均も $95 \%$ 信頼区間は 0 を含まず, 全ての值で有意な結果が得られた。抑うつ・ 不安との相関係数が正であったのは, 自責, 受容, 反 媰, 破局的思考, 他者非難であり, 負であったのは, 肯定的再焦点化, 計画への再焦点化, 肯定的再評価, 大局的視点であった。

さらに，日本人を対象とした楖原（2015）の相関係 数の值と, 本研究のメ夕分析によって得られた值を比 較したところ，抑うつと肯定的再評価，大局的視点の 関連において，榊原（2015）ではそれぞれ $r=-.33, r$ $=.00$ であったが, メ夕分析の值は $r=-.20, \quad r=-.12$ であり，いずれも $5 \%$ 水準で有意な差があった。また,

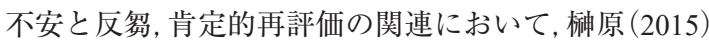
ではそれぞれ $r=.43, r=-.36$ であったが, メ夕分析 の值では $r=.29, r=-.21$ であり, 同様に $5 \%$ 水準で 有意な差があった。

\section{考察}

本研究は, メ夕分析によって CERQ と抑うつ・不 安の一般的な関連を検討した。また，メ夕分析によっ て得られた值と日本人を対象とした研究の值の比較を 通じて, 部分的にではあるが, 日本人サンプルの認知 的感情制御の特性を探索的に検討した。

\section{抑うつ・不安と正の関連を示した方略}

抑うつ・不安との間に有意な正の関連を示したのは, 自責, 受容, 反劅, 破局的思考, 他者非難であった。 以下，それぞれの結果について考察を行っていく。

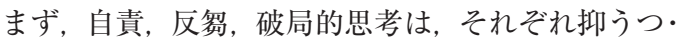
不安と有意な正の関連を示し, 絶対值も他の方略と比 べて大きかった。収集した相関係数は全て正の值で あったことから，これらの方略が抑うつ・不安と一貫 して正の関連を持つ，相対的に「不適応的な方略」で あることが, 改めて確認されたと言えるだろう。特に 破局的思考は，全ての下位方略の中で抑うつ・不安と 
Table 1

CERQ の下位方略と抑うつ・不安の相関係数の推定值

\begin{tabular}{|c|c|c|c|c|c|c|c|c|c|}
\hline & 方略 & $k$ & $N$ & $r$ & \multicolumn{3}{|c|}{$95 \% \mathrm{CI}$} & $Q$ & $p$ \\
\hline \multirow[t]{9}{*}{ 抑うつ } & 自責 & 12 & 3899 & .27 & .20 & - & .34 & 45.37 & .00 \\
\hline & 受容 & 13 & 3929 & .12 & .04 & - & .19 & 51.86 & .00 \\
\hline & 反鄒 & 14 & 4606 & .33 & .28 & 一 & .37 & 33.31 & .00 \\
\hline & 肯定的再焦点化 & 13 & 4099 & -.14 & -.19 & - & -.09 & 32.60 & .00 \\
\hline & 計画への再焦点化 & 13 & 4099 & -.12 & -.17 & - & -.06 & 34.12 & .00 \\
\hline & 肯定的再評価 & 14 & 4129 & -.20 & -.25 & 一 & -.15 & 30.19 & .00 \\
\hline & 大局的視点 & 13 & 4099 & -.12 & -.17 & - & -.06 & 37.99 & .00 \\
\hline & 破局的思考 & 14 & 4606 & .40 & .35 & - & .45 & 48.15 & .00 \\
\hline & 他者非難 & 12 & 3899 & .20 & .13 & - & .27 & 51.66 & .00 \\
\hline \multirow[t]{9}{*}{ 不安 } & 自責 & 5 & 1117 & .27 & .22 & - & .33 & 4.02 & .40 \\
\hline & 受容 & 5 & 1117 & .09 & .00 & - & .17 & 6.69 & .15 \\
\hline & 反蜴 & 8 & 1951 & .29 & .23 & - & .35 & 13.43 & .06 \\
\hline & 肯定的再焦点化 & 6 & 1317 & -.12 & -.22 & 一 & -.01 & 14.12 & .02 \\
\hline & 計画への再焦点化 & 6 & 1317 & -.14 & -.22 & - & -.06 & 9.70 & .08 \\
\hline & 肯定的再評価 & 6 & 1317 & -.21 & -.29 & - & -.12 & 11.64 & .04 \\
\hline & 大局的視点 & 6 & 1317 & -.11 & -.18 & - & -.03 & 8.34 & .14 \\
\hline & 破局的思考 & 8 & 1951 & .34 & .28 & - & .40 & 14.15 & .05 \\
\hline & 他者非難 & 6 & 1244 & .19 & .12 & - & .25 & 5.83 & .32 \\
\hline
\end{tabular}

注) $k$ : 相関係数の個数, $N$ : 相関係数ごとのサンプルサイズ, $r:$ 相関係数の平均の推定值, CI : 信頼区間, $Q$ : $Q$ 統計量, $p$; 等質性の有意性の検定結果。

の相関係数が最も大きく，精神的健康との関連におい て重要な方略であると考えられる。実際に杉浦・杉浦 （2003）は，認知療法の技法の1つである 破局的思考 の緩和 (decatastrophizing) に着目し，そのスキルが 高い個人では, 強いストレス状況でも抑うつが上昇し にくいことを示している。ただし杉浦・杉浦（2003） の尺度は, 個人がどの程度破局的思考を抑えられるか というスキルに着目したものであり，必ずしも破局的 思考そのものを測定するものではない。破局的思考の 抑制・緩和へ向けた介入を行うためには，破局的思考 そのものの性質をまず明らかにする必要がある。 CERQ の破局的思考は，現段階では破局的思考の測定 が可能な, 信頼性と妥当性を備えた唯一の尺度である。 本研究は, CERQを用いた今後の破局的思考研究に有 益な基礎的知見を提供するものであるだろう。

また，受容は，抑うつ・不安との間に，弱いながら も有意な正の相関を示した。この結果は, Garnefski \& Kraaij（2006a）において指摘されているように, CERQ の受容が, 出来事を積極的に受け入れる自己肯 定の能動的な受容（Wilson, 1996）と,「諦め」の要素 を含んだ受動的な受容（Wilson, 1996）のうち，相対 的に後者を測定するものであるからだと考えられる。 例えば，「私はその状況を受け入れなければならない と考える」や「私は起きた出来事を受け入れなければ
ならないと考える」という項目は，いずれの受容を測 定しているか, 判断が困難であるが,「私はそのこと について何も変えることはできないと考える」という 項目は, 後者を反映していると考えられる。そのため, 2つの異なる夕イプの受容のうち, 相対的に後者の受 動的な受容が強く反映され, 結果的に抑うつ・不安と 弱い正の相関を示したと推察される。しかし，仮に CERQ の受容が, こうした性質の異なる2つの受容を 測定するものであるならば，下位尺度としての妥当性 が問題とされなければならない。そのため, その因子 構造や概念の再検討を踏まえ, 適宜項目の修正などを 行っていく必要があると言えるだろう。また, CERQ を作成した Garnefski et al.（2001）において，受容が理 論的に「適応的な方略」として位置づけられていたこ とから, 受容をアプリオリに「適応的な方略」として 想定し, 調査および分析を行っている研究は最近でも 見られる (Cox \& McAdams, 2014; Vanderhasselt et al., 2014)。本研究の結果は, そうした想定が必ずしも正 しいものではないことを改めて実証的に示したもので あり，上述の 2 つの異なる夕イプの受容という観点も 含め, CERQの受容の適応性およびそれに対する研究 者の見方に再考を求めるものであると言えるだろう。

さらに，他者非難は抑うつ・不安と有意な正の関連 を示したが, 絶対值は小さいものに留まった。従来, 
他者非難は言語化などにより直接的・間接的に他者を 非難するものとして捉えられてきたが（Tennen \& Affleck, 1990), CERQ の他者非難は「私は起きた出来 事は他の人に責任があると感じる」という項目のよう に，内面で他者を非難するに留まるものである。その ため，他者を非難することによるソーシャルサポート の培失（Tennen \& Affleck, 1990）の影響が小さく，抑 うっ・不安との関連も小さくなったと考えられる。

\section{抑うつ・不安と負の関連を示した方略}

抑うつ・不安と有意な負の関連を示したのは，肯定 的再焦点化, 計画への再焦点化, 肯定的再評価, 大局 的視点であったが, 肯定的再評価以外の方略では相関 係数の絶対值が. 20 よりも小さかった。以下では, 肯 定的再焦点化, 計画への再焦点化, 大局的視点につい て，相関係数の絶対值が小さい值となった理由を中心 に考察を行う。

まず，肯定的再焦点化は，ネガティブ感情を生起さ せるような状況・出来事の代わりに，ポジティブな事 象に注意を向ける方略であり，気晴らしの一種である と考えられる。気晴らしは, 短期的には適応的な方略 であるが，長期にわたる使用は問題の先延ばしにつな がり，不適応的な帰結をもたらし得ることが指摘され ている（及川, 2003)。肯定的再焦点化も短期的・長 期的な影響が異なると考えられるが，本研究で収集し た相関係数は一時点で測定されたものであるため, 両 者の影響が混在していると推察される。そのため, 抑 うつ・不安との関連がいずれも比較的小さい值となっ たと考えられる。肯定的再焦点化は，近年注目を集め ているマインドフルネスとの関連も指摘されており (Hanley \& Garland, 2014)，CERQ による測定の試みが 今後益々増加する可能性がある。そのため, 肯定的再 焦点化の短期的・長期的な効果の検討を行い，その性 質を明らかにしていく必要があるだろう。

また，計画への再焦点化は，ストレスコーピング研 究における問題焦点型対処の一種であるが（榊原, 2014），その特徵として「私はどうしたらその状況を 変えることができるかについて考える」という項目の ように，あくまで「計画を考える」という認知的側面 に焦点化していることが挙げられる。計画への再焦点 化と抑うつ・不安の相関係数が小さな值に留まったの は，たとえ状況を改善させるための計画を考えたとし ても, 必ずしも計画に沿った対処行動が遂行されると は限らないためであろう。

さらに，大局的視点は抑うつ・不安のいずれとも有 意な負の関連を示したものの, 相関係数の絶対值は極 めて小さな值となった。大局的視点は, 他のよりネガ ティブな状況との比較を通じて，当該の状況が「まだ よい」ことを受け入れる方略であり, 状況そのものの 評価や意味を変化させるものではない。そのため，短
期的には多少ネガティブ感情が低減され得るものの, 状況そのものの評価や意味が変化しない以上，長期的 な効果はほとんどないことが推察される。いずれにし ても，大局的視点は CERQ によって初めて尺度化さ れた方略であり (Garnefski et al., 2001), メ夕分析に よって抑うつ・不安との相関係数の程度を示した意義 は大きいと言えるだろう。

以上, 肯定的再焦点化, 計画への再焦点化, 大局的 視点と抑うつ・不安の負の関連について, 相関係数の 絶対值が小さい值となった理由を中心に考察を行っ た。しかしながら，批判的な見方をすれば，これらは いずれも，下位尺度の妥当性の低さに起因するもので あるとも言える。無論, 各方略が本来的に抑うつ・不 安と大きな関連を有さないという可能性もあるため, 現段階では明確な結論を下すことはできない。しかし， Garnefski et al.（2001）以降，各方略の概念規定や項 目内容の再検討はなされていないことから，特に上述 の肯定的再焦点化，計画への再焦点化，大局的視点に 関して, 今後批判的な観点から議論および再検討を行 い，必要に応じて項目の修正を実施していく必要があ るだろう。

\section{メ夕分析の值と日本人を対象とした研究の值の比較}

メ夕分析によって得られた值と日本人を対象とした 榊原（2015）の值を比較したところ，榊原（2015）に おいて, 抑うつと肯定的再評価の負の関連がより大き く,大局的視点との関連がより小さいことが示された。 さらに，柇原（2015）に扔いて，不安と反飽の正の関 連がより大きく, 肯定的再評価との負の関連がより大 きいことが示された。こうした結果をもたらした要因 については，例えば感情経験の強度に関する文化差の 影響（Kitayama, Mesqiuta, \& Karasawa, 2006）や，項 目表現の言語間の差異などが考えられるが，現状では 日本人の CERQ のデー夕は限られており, その要因 を断定することは難しい。しかし本研究の結果は，日 本人を対象に CERQ を用いる今後の研究に貴重な知 見を示すとともに，認知的感情制御の文化的差異に関 しても一定の知見を提供するものであるだろう。

\section{本研究の限界と今後の展開}

本研究には, 以下のような限界が存在する。まず, 収集した相関係数が一時点のものであることから, 各 方略と抑うつ・不安の具体的な関係までは明らかにで きない点である。今後は縦断研究や実験的手法により, 具体的な関係性に迫る研究を行っていく必要があるだ ろう。また，各方略と抑うつ・不安の双方に関連する 要因について考慮されていない点も限界である。例え ばビッグファイブなどのパーソナリティ要因は, CERQ の各方略および抑うつ・不安に関連することが 指摘されているが（榊原，2015），実際にそうした要 
因を組み込んだ研究は少ない。今後, 各方略と抑うつ・ 不安に関連する要因を十分に検討していく必要がある だろう。さらに，抑うつと各方略との相関係数の異質 性が全て有意であるなど, 研究間での異質性が大きい ことにも注目しなければならない。こうした異質性の 要因として, サンプルの年齢, 性別, 人種や尺度の違 いなどが考えられるが，現状ではそれらの要因に迫る 十分な知見の蓄積はなく, 本研究で分析を行うことは できなかった。異質性をもたらす要因の検討は, 認知 的感情制御研究の発展につながるだけでなく, 個人の 特徵に合わせた, 効果的な方略使用を提案するなど, 臨床的な介入にも有益な知見をもたらすと考えられ る。そのため, 異質性をもたらす要因の精細な検討を 行い, それを適宜，介入へ繋げていくような取り組み が求められるだろう。最後に, 本研究はあくまで CERQ の各下位尺度と抑うつ・不安の相関係数に着目 したものであり, 個々の項目の内容やその適切性・妥 当性に関しては，十分に精査をすることはできなかっ た。既に述べたように, 特に抑うつ・不安と負の関連 を示した方略に関しては, 相関係数の絶対值が小さく, 穿った見方をすれば，これらは尺度の妥当性の低さに 起因するとも考えられる。そのため, 今後は個々の項 目にも目を向け, 必要に応じて項目の修正・追加を試 み, 尺度の妥当性を高めていく動きが求められるであ ろう。

\section{引用文献}

Aldao, A., \& Nolen-Hoeksema, S. (2013). One versus many: Capturing the use of multiple emotion regulation strategies in response to an emotion-eliciting stimulus. Cognition and Emotion, 27, 753-760.

Aldao, A., Nolen-Hoeksema, S., \& Schweizer, S. (2010). Emotion-regulation strategies across psychopathology: A meta-analytic review. Clinical Psychology Review, 30, 217-238.

Anderson, C. A., Miller, R. S., Riger, A. L., Dill, J. C., \& Sedikides, C. (1994). Behavioral and characterological attributional styles as predictors of depression and loneliness: Review, refinement, and test. Journal of Personality and Social Psychology, 66, 549-558.

Besser, A., \& Priel, B. (2010). Personality vulnerability, low social support, and maladaptive cognitive emotion regulation under ongoing exposure to terrorist attacks. Journal of Social and Clinical Psychology, 29, 166201.

Cox, K., \& McAdams, D. P. (2014). Meaning making during high and low point life story episodes predicts emotion regulation two years later: How the past informs the future. Journal of Research in Personality, $50,66-70$.

Duval, S., \& Tweedie, R. (2000). A nonparametric "trim and fill" method of accounting for publication bias in meta-analysis. Journal of the American Statistical Association, 95, 89-98.

Egger, M., Smith, G., Schneider, M., \& Minder, C. (1997). Bias in meta-analysis detected by a simple, graphical test. British Medical Journal, 315, 629-634.

Garnefski, N., \& Kraaij, V. (2006a). Relationships between cognitive emotion regulation strategies and depressive symptoms: A comparative study of five specific samples, Personality and Individual Differences, 40, $1659-1669$.

Garnefski, N., \& Kraaij, V. (2006b). Cognitive emotion regulation questionnaire: Development of a short 18-item version (CERQ-short). Personality and Individual Differences, 41, 1045-1053.

Garnefski, N., \& Kraaij, V. (2007). The Cognitive Emotion Regulation Questionnaire: Psychometric features and prospective relationships with depression and anxiety in adults. European Journal of Psychological Assessment, $23,141-149$.

Garnefski, N., Kraaij, V., \& Spinhoven, P. (2001). Negative life events, cognitive emotion regulation and emotional problems. Personality and Individual Differences, 30, 1311-1327.

Hanley, A. W., \& Garland, E. L. (2014). Dispositional mindfulness co-varies with self-reported positive reappraisal. Personality and Individual Differences, 66, 146-152.

Jermann, F., Billieux, J., Larøi, F., d'Argembeau, A., Bondolfi, G., Zermatten, A., \& Van der Linden, M. (2009). Mindful Attention Awareness Scale (MAAS): Psychometric properties of the French translation and exploration of its relations with emotion regulation strategies. Psychological Assessment, 21, 506-514.

Jermann, F., Van der Linden, M., d'Acremont, M., \& Zermatten, A. (2006). Cognitive Emotion Regulation Questionnaire (CERQ): Confirmatory factor analysis and psychometric properties of the French translation. European Journal of Psychological Assessment, 22, $126-131$.

Kàllay, É., łincaş, I., \& Benga, O. (2009). Emotion regulation, mood states, and quality of mental life. Cognition, Brain, Behavior: An Interdisciplinary Journal, 13, 31-48.

Kàllay, É., \& Vonas, G. (2001). Demographic and interpersonal characteristics of well-being in a sample of Romanian adults. Journal of Cognitive and Behavioral Psychotherapies, 11, 253-273.

Kitayama, S., Mesqiuta, B., \& Karasawa, M. (2006). Cultural affordances and emotional experience: Socially engaging and disengaging emotions in Japan and the United States. Journal of Personality and Social Psychology, 91, 890-903.

Koole, S. L. (2009). The psychology of emotion regulation: An integrative review. Cognition and Emotion, 23, 4-41.

Kraaij, V., Pruymboom, E., \& Garnefski, N. (2002). Cognitive coping and depressive symptoms in the elderly: A longitudinal study. Aging and Mental Health, 
6, 275-281.

Lannoy, S., Heeren, A., Rochat, L., Rossignol, M., Van der Linden, M., \& Billieux, M. (2014). Is there an all-embracing construct of emotion reactivity? Adaptation and validation of the emotion reactivity scale among a French-speaking community sample. Comprehensive Psychiatry, 55, 1960-1967.

Lei, H., Zhang, X., Cai, L., Wang, Y., Bai, M., \& Zhu, X. (2014). Cognitive emotion regulation strategies in outpatients with major depressive disorder. Psychiatry Research, 218, 87-92.

Martin, R. C., \& Dahlen, E. R. (2005). Cognitive emotion regulation in the prediction of depression, anxiety, stress, and anger. Personality and Individual Differences, 39, 1249-1260.

Miklósi, M., Martos, T., Szabó, M., Kocsis-Bogár, K., \& Forintos, D. (2014). Cognitive emotion regulation and stress: A multiple mediation approach. Translational Neuroscience, 5, 64-71.

Nelis, D., Kotsou, I., Quoidbach, J., Hansenne, M., Weytens, F., Dupuis, P., \& Mikolajczak, M. (2011). Increasing emotional competence improves psychological and physical well-being, social relationships, and employability. Emotion, 11, 354-366.

Ochsner, K. N., \& Gross, J. J. (2007). The neural architecture of emotion regulation. In J. J. Gross (Ed.), Handbook of emotion regulation (pp. 87-109). New York: Guilford Press.

Ochsner, K. H., \& Gross, J. J. (2008). Cognitive emotion regulation insights from social cognitive and affective neuroscience. Current Direction in Psychological Science, 17, 153-158.

及川 恵 (2003)。気晴らしの情動調節プロセス一一効 果的な活用に向けて——教育心理学研究, 51, 443-456.

Raudenbush, S. W. (2009). Analyzing effect sizes: Randomeffects models. In H. Cooper, L. V. Hedges, \& J. C. Valentine (Eds.), The handbook of research synthesis and meta-analysis (pp. 295-314). New York: Sage Publication.

Rowland, J. E., Hamilton, M. K., Lino, B. J., Ly, P., Denny, K., Hwang, E., ... Green, M. J. (2013). Cognitive regulation of negative affect in schizophrenia and bipolar disorder. Psychiatry Research, 208, 21-28.

Rukmini, S., Sudhir, P. M., \& Math, S. B. (2014). Perfectionism, emotion regulation and their relationship to negative affect in patients with social phobia. Indian Journal of Psychological Medicine, 36, 239-245.

榊原 良太 (2014)。再評価の感情制御効果と精神的健 康への影響——研究動向の概観と再評価の下位方
略という視座からの問題提起——感情心理学研 究, 22, 40-49.

柇原良太 (2015). 認知的感情制御方略の使用傾向と 精神的健康の関連——日本語版 Cognitive Emotion Regulation Questionnaire(CERQ)の作成およびネガ ティブ感情強度への着目を通して——感情心理 学研究, 23, 46-58.

柇原 良太・石井悠 (2013). Emotion Regulation Questionnaire の再評価尺度（ERQ-R）を再考する 東京大学大学院教育学研究科紀要, 53, 135-142.

Selby, E. A., Anestis, M. D., \& Joiner, T. E. (2008). Understanding the relationship between emotional and behavioral dysregulation: Emotional cascades. Behaviour Research and Therapy, 46, 593-611.

Spasojević, J., \& Alloy, L. B. (2001). Rumination as a common mechanism relating depressive risk factors to depression. Emotion, 1, 25-37.

杉浦 知子・杉浦 義典 (2003). 認知的統制のストレ ス緩衝効果——抑うつとの関連——パーソナリ ティ研究, 12, 34-35.

Tennen, H., \& Affleck, G. (1990). Blaming others for threatening events. Psychological Bulletin, 108, 209-232.

Tuna, E., \& Bozo, Ö. (2012). The Cognitive Emotion Regulation Questionnaire: Factor structure and psychometric properties of the Turkish version. Journal of Psychopathology and Behavioral Assessment, 34, 564-570.

Tuna, E., \& Bozo, Ö. (2014). Exploring the link between emotional and behavioral dysregulation: A test of the emotional cascade model. Journal of General Psychology, 141, 1-17.

Vanderhasselt, M., Koster, E. H. W., Onraedt, T., Bruyneel, L., Goubert, L., \& De Raedt, R. (2014). Adaptive cognitive emotion regulation moderates the relationship between dysfunctional attitudes and depressive symptoms during a stressful life period: A prospective study. Journal of Behavior Therapy and Experimental Psychiatry, 45, 291-296.

Viechtbauer, W. (2010). Conducting meta-analyses in R with the metafor package. Journal of Statistical Software, 36, 1-48.

Westermann, S., Boden, M. T., Gross, J. J., \& Lincoln, T. M. (2013). Maladaptive cognitive emotion regulation prospectively predicts subclinical paranoia. Cognitive Therapy and Research, 37, 881-885.

Wilson, G. T. (1996). Acceptance and change in the treatment of eating disorders and obesity. Behavior Therapy, 27, 417-439.

- 2015.4.18 受稿, 2015.11.14 受理—— 